
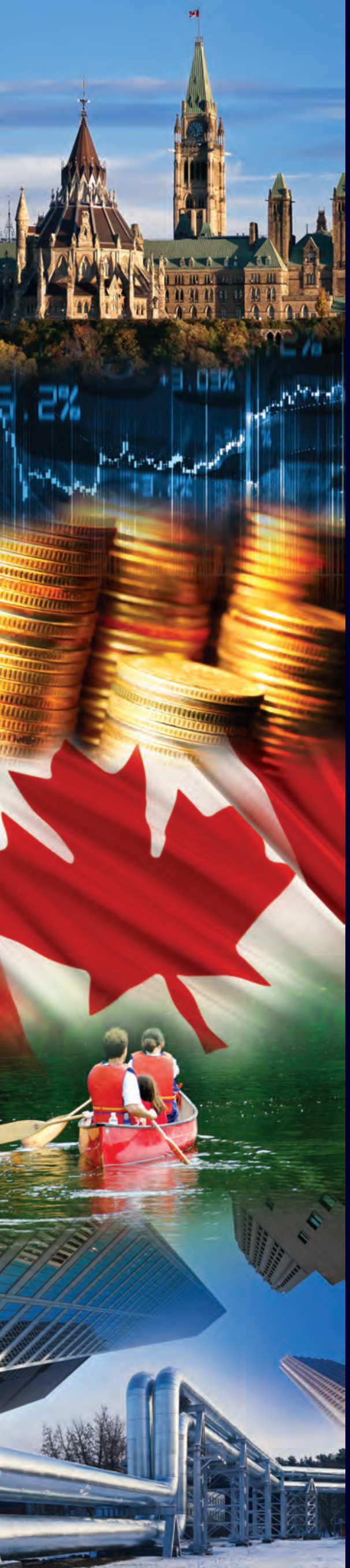

COMMENTARY

NO. 558

\title{
Choosing Canada: Canadian Cultural Policy in the Twenty-first Century
}

Canada's cultural policy goals, and the traditional tools to achieve them, have been upended by the emergence of digital competitors for Canadians' attention. A new approach is needed to connect and engage the public with Canadian content.

\author{
Daniel Schwanen
}




\section{THE C.D. HOWE INSTITUTE'S COMMITMENT TO QUALITY, INDEPENDENCE AND NONPARTISANSHIP}

\section{ABOUT THE AUTHOR}

Daniel Schwanen is Vice President, Research, at the C.D. Howe Institute.

Commentary No. 558

November 2019

Industry Regulation and Competition Policy
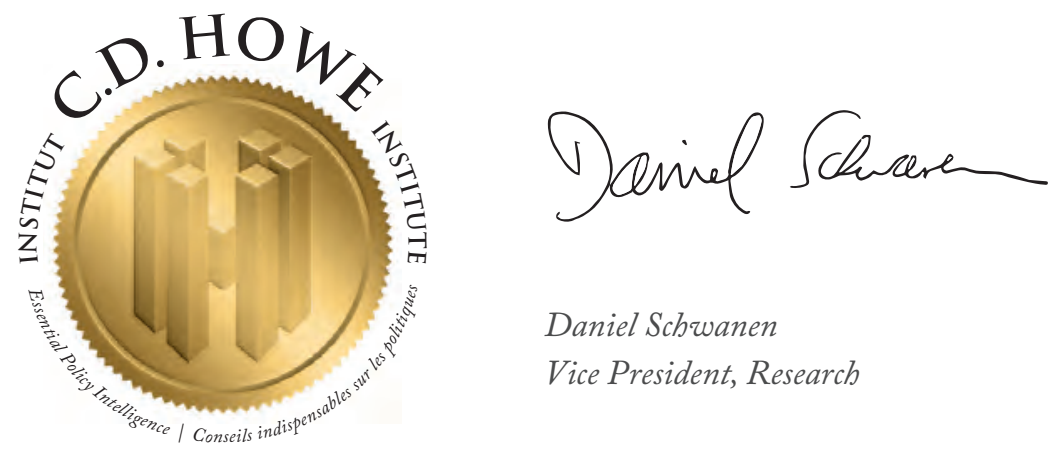

The C.D. Howe Institute's reputation for quality, integrity and nonpartisanship is its chief asset.

Its books, Commentaries and E-Briefs undergo a rigorous two-stage review by internal staff, and by outside academics and independent experts. The Institute publishes only studies that meet its standards for analytical soundness, factual accuracy and policy relevance. It subjects its review and publication process to an annual audit by external experts.

As a registered Canadian charity, the C.D. Howe Institute accepts donations to further its mission from individuals, private and public organizations, and charitable foundations. It accepts no donation that stipulates a predetermined result or otherwise inhibits the independence of its staff and authors. The Institute requires that its authors disclose any actual or potential conflicts of interest of which they are aware. Institute staff members are subject to a strict conflict of interest policy.

C.D. Howe Institute staff and authors provide policy research and commentary on a non-exclusive basis. No Institute publication or statement will endorse any political party, elected official or candidate for elected office. The views expressed are those of the author(s). The Institute does not take corporate positions on policy matters.

ISSN 1703-0765 (online) 


\section{THE STUDY IN BRIEF}

Cultural activities are central to Canadians' prosperity, identity and well-being, but the evolution and availability of digital technologies has changed the context in which Canadians access cultural content. The promotion of Canadian culture must adapt to this new setting in which content delivery bandwidth is practically unlimited, and viewers are no longer captive to legacy media.

Since access to digital cultural content uses the same broadband infrastructure as other commercial activities, policies must facilitate Canadians' access and discovery of content without inhibiting the growth of our digital economy and affordability of broadband services. In this context, this Commentary recommends that governments support the availability of diverse Canadian cultural and information offerings, promote engagement with these offerings by audiences in Canada and the world, and build a more sustainable economic framework for the cultural and information sectors by:

- Focusing more clearly the funding framework for public cultural agencies and for cultural subsidies more generally, including that for the $\mathrm{CBC}$, on the production, dissemination, and exhibition of original artistic or literary works for which a commercial market is not yet established; or for which there is a clear public rationale. A clear public rationale may include educational, informational, or community engagement benefits, or the potential to seed long-term international demand for Canadian cultural offerings.

- Working with all Canadian broadcasters and distributors of Canadian content on strategies and development to facilitate the "discoverability" of Canadian content on digitally mediated platforms, considering methods such as search engine optimization, targeted online advertising, mobile applications, and the translation of Canadian works for both foreign and domestic audiences; and encourage collaborative initiatives between content producers, broadcasters and distributors to develop and market Canadian content.

- Setting up a new "Canadian Connections Program" to streamline existing subsidies and credits not effectively aligned with the above objectives. This fund will focus instead on initiatives specifically aimed at engaging non-commercially available Canadian content with Canadian audiences. This new program would be administered through an arms' length body that would evaluate proposals based on criteria including type and diversity of content, and likelihood of engaging Canadian audiences.

- In that context, eliminate mandated funding of Canadian content by cable and satellite providers and mandatory Canadian content quotas for broadcasters, and by reducing these costs, facilitate competitively priced communications services; while ensuring a level playing field with respect to the federal taxes applied to digital services purchased by Canadians and the deductibility of advertising expenses across media;

- Reducing foreign investment restrictions applying to cultural industries, with the aim of attracting investment in Canada while retaining the ability to require of foreign investors undertakings toward boosting the financing and visibility of Canadian content.

C.D. Howe Institute Commentary $(\mathrm{C}$ is a periodic analysis of, and commentary on, current public policy issues. Barry Norris and James Fleming edited the manuscript; Yang Zhao prepared it for publication. As with all Institute publications, the views expressed here are those of the authors and do not necessarily reflect the opinions of the Institute's members or Board of Directors. Quotation with appropriate credit is permissible.

To order this publication please contact: the C.D. Howe Institute, 67 Yonge St., Suite 300, Toronto, Ontario M5E 1J8. The full text of this publication is also available on the Institute's website at www.cdhowe.org. 


\section{Canada's cultural policy is in a state of flux. This is far from simply a matter of government budgetary ups and downs, although federal spending on culture has trended down over the past decade as a share of GDP.}

A key objective of Canadian cultural policy has been to connect and engage Canadian households with Canadian cultural and information products. However, given the vast array of competing offerings available across borders through digital technologies, the ability of policy to achieve that goal reliably has been under threat for some time.

The emergence of "non-traditional" competitors for Canadians' attention, based on digital platforms that are less constrained by regulation than traditional TV or radio distributors in terms of what they can offer Canadians, has resulted in a slow but steady decline in viewership and in the number of listeners of licensed TV broadcasters and radio stations. Meanwhile, listenership and viewership of non-regulated digital offerings, many based outside Canada, such as Netflix, Spotify or YouTube, are rising sharply (see CRTC 2018, Market Insights section, figure 1 ).

These trends are negatively affecting the revenues of owners of traditional delivery platforms for culture and information products, as advertising revenues migrate to new forms of content delivery (CRTC 2018, Market Insights section, Part 3: The Financial Picture). To compound the problem, regulators still require providers of cable or satellite television services to offer a certain quota of
Canadian content in prime time and to help fund Canadian TV and film production, whereas their emerging competitors on digital platforms are not subject to these rules. Furthermore, foreign online services such as Netflix are not required to charge their Canadian customers federal goods and services tax, unlike their Canadian competitors.

Yet, in dealing with these effects, governments should be careful not to take away some of the immense benefits Canadians can derive from digital communications technologies or the use of platforms enabled by these technologies, or more generally from access to the internet. Limiting or taxing the use of these tools, which have become critical to Canadians' well-being and to Canada's future economic performance, including that of its own creative and information economy, would risk turning the country into a backwater. ${ }^{1}$ In any event, as the federal government itself has reminded us (Canada 2016, 7), "Canadians...do not want to be restricted in what they can access."

Amid these changes, many authors, filmmakers, musicians, or those who help produce and distribute the product of their work, have been able to count on quotas to boost their market and, for some, on government-mandated funding from private broadcasters. They might now wonder how to

The author thanks Grant Bishop, Lawson Hunter, Rosalie Wyonch, and anonymous reviewers for comments on an earlier draft. He retains responsibility for any errors and the views expressed.

1 To cite a policy paper by the Paris-based Organisation for Economic Co-operation and Development (Ferencz and Gonzales 2019,4), "Information and communications technology services form the backbone of the digital economy by providing the necessary network infrastructure and underpinning the digitisation of other types of services. Once services activities can be digitised, they can be transferred across electronic networks... Therefore policies that encourage competition and investment in high-speed networks are essential to unlock the full potential of the digital transformation." 
find both audiences and revenues in a much more crowded and less regulated market, in which these supportive measures are less effective or their sources dwindling. Similar questions apply to journalists who report news from a Canadian viewpoint.

The challenges facing stakeholders in the cultural sector and cultural policy itself are well known, and have been extensively analyzed, including by two recent public reviews initiated by the federal government (Canada 2018, 2019b), by the Canadian Radio-television and Telecommunications Commission (CRTC 2018) and in multiple studies published by the C.D. Howe Institute (see, for example, Hunter, Iacobucci, and Trebilcock 2010; Hunter, Engelhart, and Miller 2017; Schwanen 1997) and other think tanks (for example, Globerman 2016). Yet policymaking around them remains unsettled.

In this Commentary, I build on these public reviews - one of which is still ongoing at the time of writing, but has produced an interim report - as well as on earlier research and recent policy pronouncements, to assess the effectiveness of current cultural policy. I base this assessment first on a description of Canada's key cultural policy objectives and the tools used to achieve them. This is followed by a discussion of rationales suggested by the literature for government support of cultural activities. I then discuss whether the various policy tools the federal government uses in the pursuit of key cultural policy objectives still make sense in light of the broader rationale for supporting Canadian culture and the evolving technological and economic context, or whether better tools are available to achieve these policy objectives.
I propose ditching or revamping tools that are ill-adapted for Canada's policy objectives in the digital age. These include Canadian-content quotas for television and radio and requirements (as opposed to inducements) for the private sector to fund Canadian cultural products, as well as certain rules restricting foreign investment in Canadian cultural industries. Instead of these measures affecting mainly the supply of Canadian cultural productions, I propose an approach more focused on linking this supply with the potential demand for it. This approach would:

- facilitate the "discoverability" of Canadian cultural and information content on various platforms;

- refocus certain tax credits and parts of public funding toward a new program that would reward engaging Canadians with noncommercially available Canadian content.

- remove barriers to entry and better capitalization of cultural industries, while ensuring a level fiscal playing field for all providers of Canadian content; and

- shy away from taxes or funding obligations that would limit Canadians' access to the internet or the competitiveness of Canada's broadcasting and telecommunications sectors.

\section{WHAT IS CULTURAL POLICY, AND WHERE IS IT HEADED?}

In Canada, "cultural policy" is best understood through its two consistent and overarching objectives over the decades: ${ }^{2}$

- boosting the production of Canadian content: supporting the creation of arts, letters and

2 As exemplified by the Creative Canada Vision issued by the Department of Canadian Heritage (Joly 2017), which provides "a roadmap that focuses on supporting our creators, delivering their content to domestic and international audiences, and ensuring that there is always a space for Canadians to connect through our stories." It offers a policy framework divided into three pillars: 1. "Invest in Canadian creators, cultural entrepreneurs and their stories"; 2. "Promote discovery and distribution [of products from these Canadian creators]"; and 3. "Strengthen public broadcasting and local news." 
information such as news and documentaries ("offerings") by Canadians and/or in Canada ("Canadian content") beyond what the market would otherwise provide; and

- preferential placement for this content: influencing and even directing the extent to which this Canadian content is exhibited and the access Canadians should have to it, in preference to non-Canadian offerings.

\section{Policy Tools}

The federal government uses a number of policy tools to achieve these cultural objectives. Policies regarding film and television provide a salient example, because it is in this area that competition from US production - popular in the Canadian market and benefiting from large economies of scale in the home market - is most prominent. Among the policy tools in this sector are the following:

- ownership and financial support of the Canadian Broadcasting Corporation, Canada's national public broadcaster, whose programming must be "predominantly and distinctively Canadian";

- direct financial support to cultural agencies such as the National Film Board (NFB), Canada's public film producer and distributor, Telefilm Canada, which works to develop the Canadian audiovisual industry and products especially for television, and the Canadian Media Fund (CMF), which supports productions made for television and, increasingly, for digital media;

- requirements for private Canadian cable or satellite providers (known as broadcast distribution undertakings, or BDUs) to contribute a share of their broadcasting revenues to Canadian programming, largely through contributions to the CMF;

- quotas for the amount of Canadian content that major Canadian broadcasters must offer, including quotas specifically for evening prime time hours and for space for Canadian channels in BDUs' offerings to consumers; these quotas and related rules about the quantity and placement of Canadian content are key conditions of licenses awarded by the CRTC under the Broadcasting Act;

- mandated 80 percent Canadian ownership of broadcasters except those that distribute their programming only over the internet or mobile devices;

- a ban on takeovers of Canadian-owned and -controlled film distributors, and limiting new foreign-owned film distribution businesses to the importation and distribution of films for which they own world rights or are a major investor; in general, the Department of Canadian Heritage applies Canada's foreign investment policy in cases of proposed foreign investment in a Canadian cultural business, ${ }^{3}$ and may deny any such investment (except those below a very low value threshold) if it deems insufficient the investor's commitment to developing Canada's cultural sector (Joneja 2013, 197, 201-2);

- a refundable tax credit for Canadian-owned producers of films or television programs, based on eligible labour expenditures, in order to boost the number of competitive Canadian TV and film offerings by independent, Canadian-owned producers; and

- refundable film and video production services tax credits, based on eligible labour expenditures

3 Under section 14.1 of the Investment Canada Act, a cultural business is "a Canadian business that carries on any of the following activities, namely, (a) the publication, distribution or sale of books, magazines, periodicals or newspapers in print or machine readable form, other than the sole activity of printing or typesetting of books, magazines, periodicals or newspapers, (b) the production, distribution, sale or exhibition of film or video recordings, (c) the production, distribution, sale or exhibition of audio or video music recordings, (d) the publication, distribution or sale of music in print or machine readable form, or (e) radio communication in which the transmissions are intended for direct reception by the general public, any radio, television and cable television broadcasting undertakings and any satellite programming and broadcast network services." 


\section{Figure 1: Federal, Provincial, Territorial and Local Government Spending on Culture and Broadcasting} Services

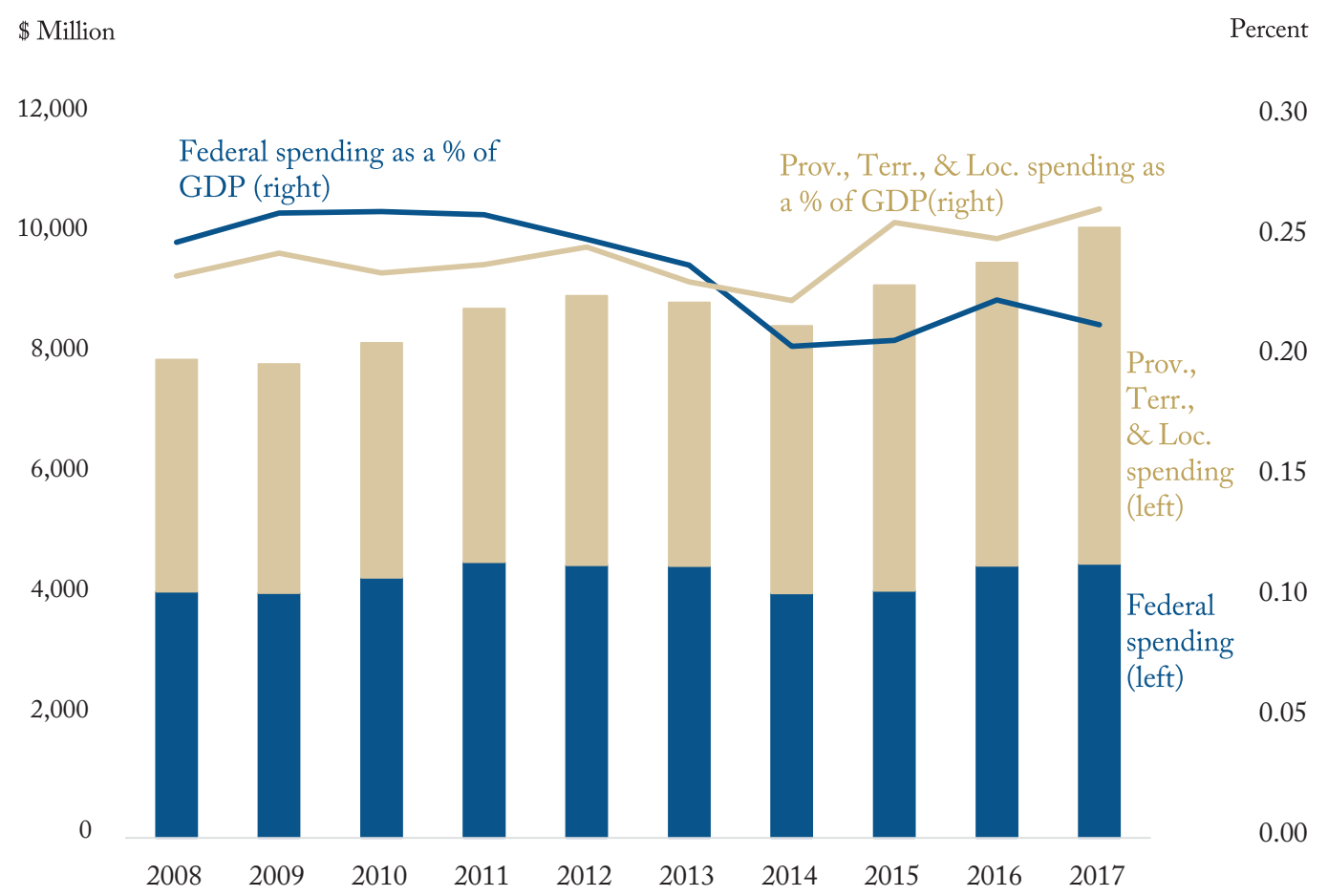

Source: Statistics Canada, Tables 10-10-0024-01 and 10-10-0005-01.

regardless of ownership of the producer, to support the capacity to make films and TV programs in Canada.

This list considers only federal policies and agencies, but provincial policies often play a key complementary role. Indeed, over the past ten years, spending on cultural activities by provincial governments has overtaken that of the federal government (Figure 1) - crucially, in the area of provincial broadcasting, which includes public agencies specializing in educational and current affairs programming such as TV Ontario, TFO and Télé-Québec. Provinces also offer tax credits for audio-visual productions in their jurisdictions, complementing those offered by the federal government.

\section{Recent Official Policy Reviews}

The federal government formed after the October 2015 general election was seized with the future of cultural policy, especially as it intersects with digital technologies. It has responded with two public reviews. The first, launched in April 2016 under the aegis of Heritage Canada, focused on Canadian content in a digital world. It yielded the Creative Canada vision in September 2017 (Canada 2017). The second review, focusing on Canada's 
broadcasting and telecommunications legislation, was launched in June 2018 under the aegis of Innovation, Science and Economic Development Canada (ISED), and its report is due by the end of January 2020. As well, the government announced significant financial support for Canadian news media, which, among other measures, will take the form of tax credits toward the cost of producing original news content. Anticipating these developments, the CRTC had conducted its own "Let's Talk TV" consultations, starting in October 2013, which ended with a series of decisions in March 2015 that aimed to be consumer friendly while testing new models of funding and launched a discussion on the "discoverability" of Canadian content across a range of platforms used by consumers (CRTC 2015).

Of the Creative Canada report, it is fair to say that did not garner a consensus. This was not, of course, because of its proposed additional cash investments in Canadian productions via increased funding for the CMF. Critics focused on Minister Mélanie Joly's embrace of Netflix's promise to invest $\$ 500$ million in original Canadian production over five years, as a key plank for supporting Canadian culture in the digital age - but exactly what Netflix would fund and even whether it constituted incremental funding was not clear (Taylor 2018). ${ }^{4}$ Critics also decried the report's businesslike emphasis on embracing technology, entrepreneurship and exports as engines of growth in cultural industries, with little reference to the kind of content or the importance of culture as such (see, for example, Wells 2017).

Historically, many cultures and cultural creators have thrived by embracing technology, by being entrepreneurial and by expanding their audiences beyond their local market. A mid-sized market like Canada can help nurture artists with global ambitions - but fulfilling them requires the drive and wherewithal to project their creation beyond the domestic market, which often implies being commercially oriented. Modern technology has a key role to play here by making the works of Canadians more easily accessible than before to larger audiences: virtual trade in cultural products is growing much faster than physical trade (UNESCO 2019).

From that perspective, Creative Canada's approach to marketing Canada's cultural production abroad makes sense, as it would for any type of economic activity for which economies of scale or scope are important. Indeed, in her speech launching Creative Canada, Minister Joly extolled the success of Canadians on the New York Times bestseller list, at the Emmys or Oscars or in the video game or post-production industries. Yet, the more successful Canadian creators and cultural workers and businesses are, the less they need to rely on protection or to be subsidized at home. Practically in the same breath, however, the minister bemoaned the "new wave of information" brought by Facebook, Netflix, Spotify and YouTube that can "drown out our content" - even though many contemporary Canadian singers, for example, became international successes in part by using such platforms.

The critics and Minister Joly's own speech thus point to a dual reality: Canadian artists can become US or even global successes, but does that actually "protect and promote our stories and our culture," which the minister set as a key goal of cultural policy? For this, a focus on the domestic market albeit with tools that recognize the integration of the domestic and global markets via the internet in particular - remains central, as also pointed out by the minister and as I elaborate on in this Commentary.

4 Netflix seems willing to make public the amounts it spends by country, perhaps as a way to differentiate itself vis-à-vis powerful emerging rivals in these markets (see Sweeney and Conlan 2019). 
In also calling for a review of the Broadcasting, Telecommunications, and Copyright acts, Creative Canada recognized that modernizing cultural policy for the digital age requires addressing the entire legislative framework affecting the policy, and it anticipated the second review currently under way. Indeed, the 2017 federal budget had already announced a review and modernization of the Broadcasting and Telecommunications acts.

In June 2018, the federal government appointed an external panel to conduct this review of Canada's communication legislative framework (Canada 2019b). The framework in this case means the Telecommunications Act and the Radiocommunications $A c t,{ }^{5}$ both of which fall under ISED, and the Broadcasting Act, under the Department of Canadian Heritage. A separate review of the Copyright Act was launched in December 2017 and is still under way.

The mandate of this Broadcasting and Telecommunications Legislative Review (BTLR) speaks not only of ensuring "that Canadians continue to benefit from an open and innovative Internet," but also of examining "issues such as telecommunications and content creation in the digital age, net neutrality and cultural diversity, and how to strengthen the future of Canadian media and Canadian content creation" (Ibid.). In effect, it is dealing with a lot of the unfinished business left by the earlier digital age review.

The BTLR produced an interim report (BTLR 2019), based on its consultations across the country. However, without waiting for the final report, the minister of Canadian heritage declared that "web giants" will be "required to create Canadian content + promote it on their platform" (Menzies 2019). While continued support for Canadian audio-visual content is a message that features prominently in the BTLR's interim report, it is unclear how Canada can force web giants to contribute to it without raising the costs or diminishing the potential benefits of Canadians' access to the internet, which would go against the BTLR's mandate.

There is, in short, still a need to clarify the interface between cultural policy and a proconsumer policy direction that would ensure the best access to what the Internet has to offer and other benefits of a competitive telecommunications system. This need is increasingly pressing. Without such clarification, Canada risks taking highly ineffective policy courses on both fronts.

To help clarify this interface, especially from the viewpoint of cultural policy, it is useful to take a step back and return to the fundamental rationale for cultural policy itself. This will help us understand what underpins the two overarching objectives described above and how specific tools can help Canada achieve these objectives effectively.

\section{THE RATIONALE FOR A CANADIAN CULTURAL POLICY}

The increasing ease with which Canadians' attention could be captured by US popular culture, starting in the 1920s initially through the spread of radio, then television and now through digital platforms, was and continues to be the key catalyst behind Canadian governments' policies on culture. In 1936, the minister of communications, C.D. Howe, introduced the Canadian Broadcasting Act, which created the $\mathrm{CBC}$ as the national broadcaster. This move was intended to address concerns that private Canadian radio stations would affiliate

5 As von Finckenstein (2017) notes: "Any review of communications has to include the Radiocommunications Act which presently governs spectrum management and wireless communications. All communications, regardless of mode, should be covered by one communications act. The present division between wireline, wireless and cable communications predates the digital revolution and makes no sense in the age of the internet." 
themselves with US networks and air programing already produced for the US market, which would block the opportunity for Canadian programming to reach Canadian audiences, given limited channel availability at the time. Yet, soon after the CBC's creation, private radio stations were complaining that it was taking business away from them by running US and commercial programs itself, and they demanded that the $\mathrm{CBC}$ become a strictly public service radio (Canadian Communications Foundation 2019).

This story provides an almost timeless illustration of the dynamic tension at the core of Canadian cultural policy between (i) the concern that stories, news and other cultural and information products made by Canadians, might not be as easily accessible to Canadian audiences as foreign content, and (ii) the business drive to bring to Canadian audiences programming (or printed matter) already developed for the much larger US market, since the latter are typically less costly per likely audience than the equivalent Canadian cultural products.

Nevertheless, it is not clear why this abundance of foreign programming should be a problem for the Canadian public, who in this day and age could just search for or demand alternative content should they not enjoy or get value from what they are watching. The question of what benefits Canadians might derive from a policy that tilts the available offerings toward more artistic, entertainment or information products from their own culture periodically needs to be asked - and answered.

\section{Positive Externalities from Culture and Information}

Certain rationales exist for governments to support cultural activities that also apply in the specific case of Canada. These are based on the idea that the private market - facing demand from buyers of cultural goods and services guided by their own preferences and budget constraints, and supply by providers that consider only their own private cost of producing it - will underconsume or underprovide cultural goods or services. That is because such consumption or production can generate positive effects for others, or positive externalities, that private buyers or sellers will not take into account. (For a fuller discussion of these, see Payne 2003, 9-20; Schwanen 2001, 4-7; see also Hunter, Iacobucci, and Trebilcock 2010, table 1). These externalities are:

- the transmission to future generations of distinct Canadian stories and cultures that, it is surmised, benefit current and future Canadians, including the very continuity of a Canadian polity and of Canadian cultural communities in their various manifestations;

- the availability and accessibility of information such as news and documentaries or stories emanating from Canada and its diverse communities, which can promote vital understanding about and goodwill towards Canada, or provide information about what events mean for Canadians, enabling Canadians to make choices based on information that is relevant to them;

- activities that promote the sharing of common experiences among Canadians - such as festivals or cultural gift giving, or tracking the progress of Canada's amateur and national sports teams - which can build "social capital," defined by Robert Putnam (1995) as "norms and networks of civic engagement," and which in turn reduces the cost of other useful interactions among Canadians; ${ }^{6}$

- the increasing enjoyment of life by individuals who acquire more refined cultural tastes (culture as a "merit good") or simply discover new ways to improve their standard of living as a result of exposure to different types of cultural offerings; in that sense, cultural programs that divert attention

6 For a reflection on the current state of social capital in Canada, see Valpy (2013). 
away from mass culture play a role akin to that of education;

- the local capacity to create artistic products, enjoy artistic experiences or receive an arts education, can enhance Canadians' standard of living beyond that strictly recorded in the market for cultural activities, and historically has been the foundation of new sources of wealth - for example, by facilitating the creation of more innovative and hence more valuable design and advertising, which in turn appear vital to Canada's ability to overcome its lesser ability than that of many peer countries to commercialize ideas. This rationale is akin to the argument for subsidizing research and development (R\&D). ${ }^{7}$

These externalities fit squarely within the framework of economic analysis, but they also span the broader question of the role of cultural policy in maintaining what is distinctly valuable about Canada and its cultures. As 1972 Nobel laureate Kenneth Arrow argued, if information that is cheap and omnipresent is not relevant to the choices facing a particular organization, that organization can become "non-agenda," and hence become irrelevant even to its own members (Arrow 1974). The same would apply to communities. In sum, the idea is that Canadians' exposure to Canadian cultural and information products and their capacity to produce art and other cultural goods or services generate positive externalities for Canadians as a whole.

Absent hard calculations of the value of many of these externalities, ${ }^{8}$ whether a cultural good or service receives a subsidy ultimately depends on voters' attitudes (Payne 2003, 26-7). There are, however, intermediary mechanisms that can help gauge the value to the public of government support for an activity. Encouragement by government, via tax incentives, of philanthropic donations to cultural pursuits, for example, has the enviable quality of supporting activities that the wider community, as opposed to the bureaucracy or recipient cultural groups, has clearly decided are worth it. Other indicators that support passes a "public benefit" test would be the public's interest in, expert acclaim for, or even unexpected practical application of the work the policy has supported.

\section{Cultural Policy and Canadian Values and Identity}

Cultural policy ultimately aims at facilitating the projection of Canadian creativity, arts and information into the wider society and economy, and in that sense it emanates from and supports Canadian identity or identities. That role, however, should be clearly separated from the idea that there might be "Canadian values" whose proponents might be more worthy of support through cultural policy than those who do not share them.

Canadian values and identity have always evolved, and to promote one version over others would run counter to the rationale for cultural policy described here. Indeed, Kymlicka (1991) argues that cultures must be able to evolve to thrive, which does not mean they cannot remain distinct. Blocking access to non-Canadian cultural products on the grounds that some official or even voters

7 As well, many cultural products, especially audio-visual items and books available digitally, exhibit key characteristics of "public goods," defined as goods that can be enjoyed by more than one person at the same time at no additional cost per person, beyond the sunk cost of making the initial product, and for which it is difficult to exclude anyone from enjoying. Given that pricing in private markets is based on marginal cost, the public good might not be produced without government support of these sunk costs (Payne 2003, 6-8; Grant and Wood 2004, Appendix B). Indeed, they share these characteristics with knowledge generated by R\&D spending.

8 And even if these positive externalities - that is, social benefits in addition to the private benefits accruing to those that might receive a subsidy - could be quantified, taxing other activities to subsidize cultural activities creates a deadweight economic loss, and so the perceived public benefits of cultural activities should at least compensate for that loss. 
do not like the values they represent is a poor way to preserve the cultural identity of any group of Canadians. Only if the non-Canadian content were so pervasive and channels to access Canadian content so limited that Canadians were prevented, as a result, from becoming aware of domestic content that they might otherwise value, might restricting access to it be warranted.

\section{Cultural Industries' Share of Economic Activity Is Not the Issue}

When seeking to convince Canadians of the importance of supporting Canadian cultural content, official documents or speeches more often than not trumpet the contribution to Canadian jobs or to Canada's gross domestic product (GDP) of the industries that produce this content. ${ }^{9}$ In a similar vein, the role that cultural products play in Canada's export performance is touted as a sign of success. ${ }^{10}$ These metrics are offered both as a sign of success and as proof that cultural activities writ large are worthy of additional support and protection.

Certainly, cultural jobs and exports are valuable. By these standard economic metrics, however, they are no more worthy of special support than a dollar produced or a job created in another sector of the economy. If those are the metrics, Canadians might well ask what is so special about cultural industries that they, and not some other industry, deserve special support.

This is not to say that run-of-the-mill measures of economic activity are not useful for some purposes. Knowing the importance of cultural industries and occupations in a particular area can be useful for tourism planning, for example, or to attract individuals and businesses that value a rich cultural environment. As with $\mathrm{R} \& \mathrm{D}$, it is difficult to predict the ultimate success of the work that goes into developing a new cultural offering, which might partly explain the focus on metrics of activity, as opposed to success in connecting with the public. But for activities that require constant public subsidization and protection, success ultimately should be gauged by metrics that are reasonably related to the public rationale for such support and creating jobs or GDP in the cultural industries does not primarily fit that bill.

As we have seen, the key rationales for cultural policy are the positive externalities Canadians are presumed to enjoy from Canadian cultural and information offerings. The benefits of such cultural activities are essentially realized when Canadians choose to enjoy, consume, share or build successful economic activities on these Canadian offerings. But are the tools currently used to support cultural policy doing so in ways best aligned with the rationales for having a cultural policy in the first place? If not, what other policy tools might be more effective.

\section{THE EFFECTIVENESS OF CULTURAL POLICY TOOLS}

Inherent to the functioning of Canadian cultural policy is the differentiation between Canadian and non-Canadian content. That is because what generates the expected positive externalities - when the content is produced, viewed, read or listened to by a Canadian or by a foreign audience - is its quality of being Canadian. In many instances, the

9 Thus, in its opening two paragraphs, the 2019-20 departmental plan of the Department of Canadian Heritage states: “The Government of Canada is committed to promoting Canada's artists and creative and cultural industries...Canadian Heritage and its portfolio organizations play a vital role in the...economic life of Canadians. Arts, culture and heritage represent $\$ 53.8$ billion in the Canadian economy and more than 650,000 jobs” (Canada 2019a, 2).

10 As the glowing description of international success by Canadian artists and the announcement of a first Creative Export Strategy as part of the Creative Canada Initiative made clear (Joly 2017). 
market would cater naturally to the value consumers attach to being able to differentiate between otherwise identical or similar products according to their place of origin. An example is diamonds that exhibit the "Canadamark" in contrast to others that might be less responsibly mined. But the fact that positive externalities arise from exposing Canadians $^{11}$ to Canadian cultural or information offerings implies that the market, left on its own, would underconsume or underprovide these. In turn, government policy, if it is to correct for this state of affairs, needs to be able to use tools that differentiate between a film or magazine that is Canadian and one that is not, even though both are otherwise similar products that compete for buyers' wallets, time and attention.

International trade agreements limit what Canada can do in this respect, but not fatally so. Under Article III of the General Agreement on Tariffs and Trade (GATT), for example, Canada cannot impose taxes on foreign goods that are "like" or "directly competitive or substitutable for" domestically produced goods. To Canada's dismay, in 1997 the GATT Appellate Body ruled that a news magazine with mainly US editorial content, but whose advertising was aimed at the Canadian market, was a directly competitive or substitutable good with a newsmagazine with mainly Canadian editorial content, and therefore Canada could not impose an excise tax only on the former (WTO 1997. For discussion, see Browne 1998; Schwanen 2001, 12-14).

Canadian trade policy has evolved considerably since the GATT was implemented in 1947, and
Canada has now negotiated blanket "cultural exemptions" in trade agreements such as the North American Free Trade Agreement (NAFTA). ${ }^{12}$ It also refused to make commitments regarding the liberalization of trade in cultural services in the General Agreement on Trade in Services (GATS), which came into effect in 1994. Of course, Canada pays a price for these positions in terms of access to foreign markets that it might have been able to obtain in exchange. Still, GATT rules do not prohibit the subsidization of domestic cultural (or any other) production, as long as this is not in the form of export subsidies or conditional on the recipient's using a domestic rather than an imported good.

International trade rules do, however, shape the specific measures Canada can adopt. The truce declared in the magazine dispute, following the signature of the GATS, allowed Canada to limit the deductibility of advertising expenses incurred in periodicals to those incurred by periodicals with a high percentage of original Canadian editorial content, in turn defined as content authored by a Canadian citizen or permanent resident and created specifically for the Canadian market. This worked under trade rules because the new Canadian measure affected advertising services, not periodicals as a good.

The resolution of the magazine dispute involved a fairly streamlined definition of "original content" produced by Canadians and aimed at the Canadian market. ${ }^{13}$ But what qualifies as Canadian content for the purpose of applying content restrictions or eligibility for subsidies will vary across media

11 In many cases, exposing foreign audiences as well - for example, through the benefits that can accrue to Canadians generally from cultural diplomacy or cultural tourism in Canada, the scale of cultural activity that export success can enable, or a strong Canada "brand."

12 The Canada United States Mexico Agreement that is meant to supersede the NAFTA, but is not yet in force, also includes a cultural exemption.

13 For rules on the deductibility of advertising expenses with periodicals or broadcasters, see Canada, Justice Laws Website, at https://laws-lois.justice.gc.ca/eng/acts/i-3.3/page-17.html. 
and programs. For music, current rules are fairly clear and concise: under the so-called MAPL system, a piece that meets two of the following four conditions qualifies: the Music is composed by a Canadian, the Artist is Canadian, the Performance is recorded or takes place in Canada and the Lyrics are by a Canadian. A TV program will be certified as Canadian if the producer, key creative functions (based on a points system), the director or screenwriter and one lead performer are Canadian, and a minimum of 75 percent of expenses are paid for services provided by Canadians or Canadian companies. (There are exceptions for international co-productions.) Rules governing what counts as Canadian for the purpose of eligibility for subsidies and tax credits can be even more complex. And rules limiting ownership or control of a sector or activity to Canadians can act as substitutes for content rules, on the theory that Canadian control is more likely to yield quality Canadian content, a theory to which I return below.

For the purpose of meeting the rationale of cultural policy - which is to generate the positive externalities discussed above through the willing use or enjoyment of Canadian content - a simple operational definition of Canadian content should suffice to guide policy across the board. I propose that "Canadian content" be defined as an artistic, literary or information offering of any kind:

- whose moral rights accrued initially to a Canadian permanent resident; or which depicts a performance given in Canada or predominantly by Canadian permanent residents; or which is produced on behalf of a Canadian government or public institution; or which largely and fairly documents any aspect of Canada as it is or was; or

- developed for a mostly Canadian audience, and is produced mostly by Canadian residents (or is an approved co-production under agreement with another country).

How effective, then, are the specific tools used to promote Canadian content?

\section{Requirements of Licensed Broadcasters}

Canadian-content quotas on television and radio seek to enhance the ease with which such content is available, relative to non-Canadian content, in the hope that Canadians might appreciate Canadian content more than they would have a chance to otherwise. Distributors of TV programs over the air, via cable and satellite, and over the internet via internet protocol TV (IPTV) ${ }^{14}$ are also required to contribute a portion of their revenues to fund Canadian audio-visual productions. Such obiligations do not apply to providers of streaming and other services over the internet.

As Canadians embrace new technologies and platforms to access their entertainment and information, the ability of quotas to affect Canadians' viewing or listening habits is rapidly diminishing. Indeed, 2013 marked the first year in which the number of Canadian households subscribing to internet services exceeded the number of traditional television subscribers. Although 75 percent of Canadian households still subscribed to cable or satellite television distribution services in 2016 - down markedly from 83 percent only four years before -87 percent of Canadian households subscribed to internet services (CRTC 2019 , figure 1.1). In the economy more generally, the culture, entertainment and information services offered online through digital technologies have boomed relative to other economic activities, and in particular relative to traditional cultural and information businesses (Figure 2).

14 "Pirate" IPTV providers, as the name implies, operate outside of and in competition with regulated broadcasters and owners or licencees of content. 


\section{Figure 2: Gross Domestic Product in Information and Cultural Industries}

$2008=100$

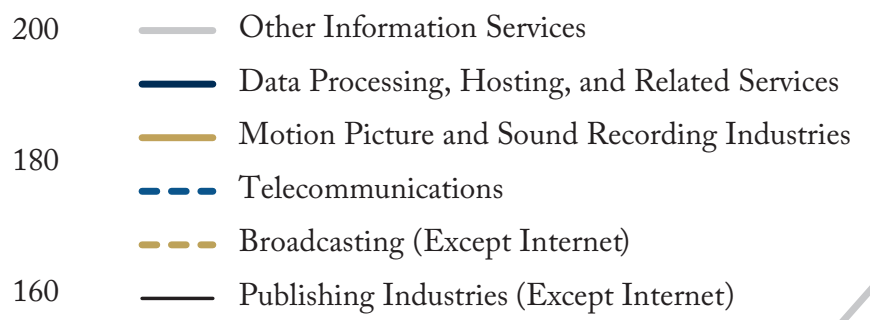

140

120

100

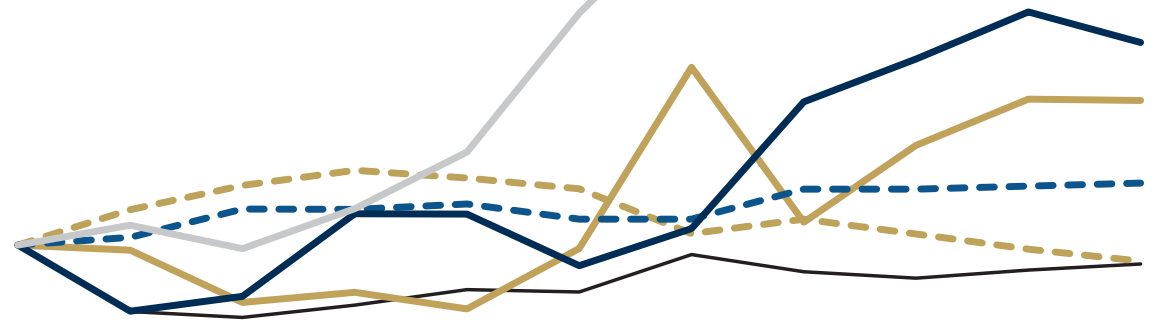

80

60

\begin{tabular}{lllllllllll}
\hline 2008 & 2009 & 2010 & 2011 & 2012 & 2013 & 2014 & 2015 & 2016 & 2017 & 2018
\end{tabular}

Thus, content providers' access to Canadian households via traditional "push" platforms that enable the content available to households to be programmed and controlled is clearly declining. Through platforms offering a vast trove of content, Canadians can "pull" the content of their choice from practically anywhere, on a multiplicity of devices (Hunter, Iacobucci, and Trebilcock 2010 provide a good early exploration of the dynamics of "pull" vs. "push" platforms). Advertising revenues have followed the rise of the internet, eclipsing those of all traditional media (Hunter, Engelhart, and Miller 2017, 14-15). Broadcast distributors themselves have responded to emerging competition by offering "on-demand" services, further moving away from the model that allowed content to be pushed to Canadian households. In this context, requiring them to provide certain content, including a specific quota of Canadian shows or music during prime time, can only make them lose even more steam relative to competitors that cannot be regulated in that way.

According to Statistics Canada, in 2015 Canadians spent almost five hours per day on average primarily on leisure (Statistics Canada 2017). And increasingly, that time is spent using computers. The playing of video games alone increased from virtually nothing in 1992 
to almost three-quarters of an hour per day per Canadian age fifteen and older in 2015. Purely in an accounting sense, this increase seems to have come at the expense of other leisure and voluntary activities, including arts and crafts, reading, watching television and "socializing." Moreover, the generational aspects of this change are striking: only the aging of the population prevents a more pronounced average trend toward digital entertainment and access to information.

Broadcast distributors and providers of communications services are often one and the same company, as many firms have sought to exploit synergies across the two industries (see CRTC 2019, figure 3.7). As such, they must not only meet the competition for Canadians' attention from a practically infinite number of sources; they must also deliver modern, accessible and competitively priced communications and information infrastructure - in particular, good access to the internet - that is vital to Canada's economic future and that Canadians demand. These companies, however, are seeing their broadcasting revenues decline while their revenues from telecommunications grow (CRTC 2019, figure 3.2).

In the bygone world of a finite number of channels, each with a set schedule of offerings, the power of licensed broadcasters to generate abovemarket returns using non-Canadian programming (available relatively cheaply) could well have justified the obligation put on them to exhibit Canadian cultural content (Hunter, Iacobucci, and Trebilcock 2010, 21-2). But in the now ferociously competitive context for reaching audiences - and in which Canadians have a wide array of choices for enjoying Canadian cultural content - not only are quotas quickly losing their traction; they are harming the ability of Canadian distributors who are subjected to those rules to compete for Canadians' attention and business, often against foreign-based entities. The same is true of obligations to support the production of Canadian content: they are a subsidy to the media production sector paid by a captive domestic broadcasting sector, and hence also by the major companies in the telecommunications sector, beyond the amounts they already spend of their own volition on Canadian programming that connects with its audiences. These policies harm Canadians' incomes more generally by, in effect, subsidizing sectors whose productivity is relatively sluggish at the expense of ones whose productivity is higher, thus impeding Canada's overall productivity performance, on which Canadians' standards of living depend (Figure 3).

According to many observers (see, for example, von Finckenstein 2017), it is time to devise communications policies that do not make Canadians pay for content they do not watch via compulsory contributions, regulations or special taxes that only hamper the capacity of the Canadian communications system to provide access to the internet, or more generally to provide modern communications infrastructure and services, that are central to the future of Canada's economy and Canadians' participation in it. These considerations are not lost on governments and regulators. Through the public consultations mentioned above and a recent report by the CRTC on the future of programming distribution in Canada (CRTC 2018), the federal government and the CRTC have been preparing both the cultural industries and the public for a profound revamp of the way cultural policy functions in Canada, particularly with regard to the distribution and funding of audio-visual products.

\section{Deductibility of Advertising Expenses}

As we have seen in the discussion on the CanadaUS magazine dispute, Canadian businesses can deduct the cost of advertising placed in Canadian periodicals containing a certain amount of original Canadian content. The rules are somewhat different with respect to broadcast advertising aimed primarily at the Canadian market. In this case, the broadcaster must be Canadian for the expense to be deductible by the business doing the advertising. 


\section{Figure 3: Labour Productivity in Information and Cultural Industries}

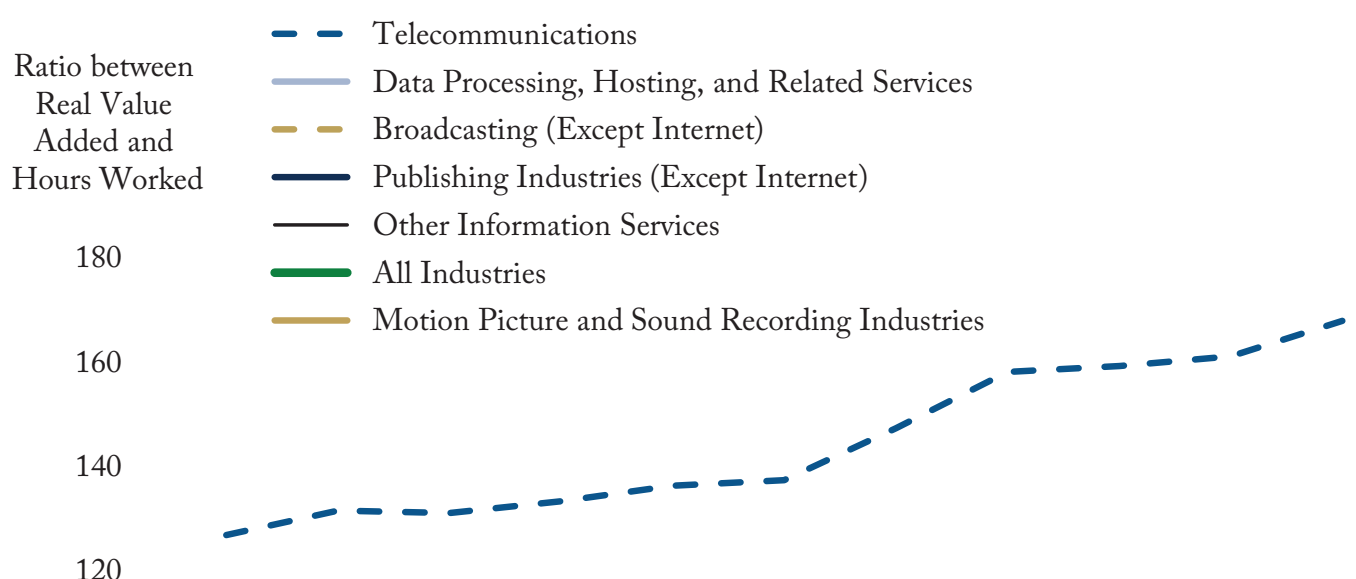

100

80

60

40
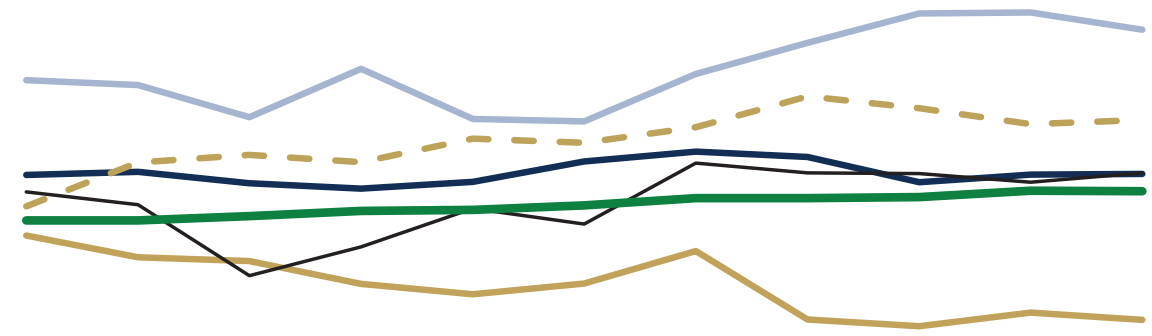

20

0

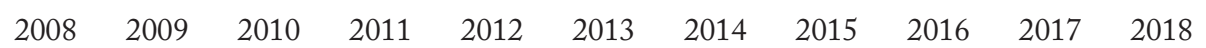

Source: Statistics Canada, Table 36-10-0480-01.

Since the advent of the internet, Canadian businesses have had more avenues to reach their customers. Web-based services are not considered to be broadcasting by the Canada Revenue Agency, and therefore Canadian businesses may fully deduct those advertising expenses from their income. Although many web-based services on which Canadian businesses advertise are not Canadian, disallowing altogether the deductibility of advertising expenses incurred on these platforms would simply throw Canadian businesses under the bus against their foreign competitors. It would make it more difficult to reach their domestic market, and in general limit the growth of an industry, advertising, that employs a large share of Canada's cultural workers and has often contributed to generating a positive Canada "brand" on par with other cultural industries.

At the same time, we should encourage a level fiscal playing field between different players offering advertising-supported cultural content. From that perspective, the policy should be to allow Canadian advertisers to deduct only advertising expenses placed with any entity, Canadian or 
foreign, that pays Canadian sales and income taxes commensurate with its business in Canada. ${ }^{15}$

\section{Public Subsidies and Tax Credits for Private Cultural and Information Productions}

It is impossible to discuss in detail here the numerous subsidies available to support cultural activities in Canada. ${ }^{16}$ However, one should broadly distinguish those programs meant to support individual artists, new creations and cultural innovation - for example, experimentation with digital technologies - or to connect cultural productions to their audiences, from programs that are more clearly directed at supporting economic activity in certain sectors, often to shield them from the effect of competition.

Two cases exemplify the latter: the Canadian Film or Video Productions Services Tax Credit, and the recently introduced tax credits to support the creation of original news content in traditional media. Both are subsidies to labour costs incurred by the private sector. They essentially support jobs in these sectors, without any reference to the Canadian-ness of the content in the former case and in either case without reference to future success in connecting Canadian culture or information with Canadian audiences.

The rationale offered for the film or video tax credit revolves around the need to maintain an audio-visual industry of a scale that can compete with US and other global production facilities.
The idea here is that, without such scale, Canada's ability to produce quality and attractive audio-visual content would be impaired. And this, it is true, might in turn impair the attainment of cultural policy objectives, notwithstanding the increasing ability of content producers to create effective audio-visual offerings using lower-cost digital technologies. If industry players want to scale up, they need only look at the large market next door, which many Canadians know intimately, which they can access easily, and to which in fact Canadian cultural industries, and its audio-visual industry in particular, already export successfully. ${ }^{17}$

The need to compete against the large number of US states that offer tax credits and other incentives for audio-visual productions can also be invoked as a reason to subsidize local Canadian audio-visual efforts. This would be an example of a "second-best" case for supporting an industry: Canada might well have some natural advantages in competing for such business, but US subsidies pull some of that activity south, creating an inefficient allocation of North American resources. If Canadian locations did not offer similar inducements, they would lose activities that economic efficiency would otherwise dictate be located in Canada. ${ }^{18}$

The recent announcement of large private investments in a film and television production studio in Hamilton very much falls in that category, with the investors touting Ontario's audio-visual production tax credits and Canada's tax credits, in addition to other attractive local features and

15 On sales taxes as they apply to foreign-owned digital businesses, see Wyonch (2017). Regarding income taxes, what constitutes a fair share of taxes to be paid in any given country by a multinational company that books its net income in lower-tax jurisdictions is currently the subject of negotiations under the "Base erosion and profit shifting" initiative at the OECD, which aim to conclude by 2020.

16 For a list of these programs, see Canada, "Funding - Culture, history and sport," online at https://www.canada.ca/en/ canadian-heritage/services/funding.html.

17 A point prominently made by Heritage Minister Joly (2017).

18 However, the cornucopia of US programs that have emerged since the late 1990s actually started as a response to "runaway" film productions attracted by Canadian film production incentives. In such tit-for-tat situations, a more efficient outcome might be achieved if everyone stopped subsidizing. 
supportive partnerships, as a key reason for their investment (Canadian Press 2019). However, with the economic boost flowing from cultural subsidies falling mainly locally, and their main justification being the need to compete against local US subsidies for similar activities, production services tax credits offered by the federal government that are not tied to particular Canadian-content requirements should be offered only when matching existing local or provincial subsidies apply.

The media support fund, initially announced in Finance Minister Bill Morneau's fall 2018 fiscal update, will distribute hundreds of millions of dollars over the next five years to subsidize the salaries of journalists from certain media outlets and other costs of producing and disseminating original news content. As well, not-for-profit news organizations will be able to issue charitable tax receipts, as long as they make their content available for free, and a non-refundable tax credit will be created for subscriptions to Canadian digital news (Zimonjic 2019).

The plight of traditional news media, which have seen advertising revenues melt away to the benefit of internet-based platforms, ${ }^{19}$ is well known. The question of how to maintain viable independent news media - given the importance of a diversity of viewpoints, but also heightened concerns over the manipulation of content disseminated by interested parties under the guise of independent content - has preoccupied a number of governments around the world. Nevertheless, the main issue with subsidizing the jobs of journalists working for traditional news media is that it does not encourage the public to connect with these media, which is how such support could have a positive effect from the viewpoint of cultural policy. The suggestion by the Journalism and Written Media Independent Panel of Experts
$(2019)^{20}$ that the federal government spend more in advertising in traditional media likewise raises the question of why advertise at all in a particular medium if it does not effectively reach the advertiser's intended audience.

Although public support for organizations that generate Canadian content that Canadians will actually absorb and the tax credit for subscriptions to Canadian digital news fit the objectives of cultural policy, the subsidization of specific industries, of the labour costs they incur, or even worse, of some organizations but not others should be scrapped as not justifiably contributing to the goals of Canadian cultural policy. Such subsidization should be replaced by eligibility for the broader package I propose below for connecting Canadian news and cultural content to the Canadian public, irrespective of the means of delivering the content.

\section{State-Provided Content}

Cultural production by agencies of the federal and provincial governments has tended to fit the rationales for cultural policy fairly closely, whether experimental (NFB) or educational (TV Ontario) or to connect Canadians with other Canadians across the country (CBC). That is to say, they arguably provide cultural benefits in the public interest that complement Canadian cultural offerings from the private sector.

As noted, however, the goal of educating and connecting Canadians with one another can be achieved only if Canadians willingly partake of or engage with the proposed content. The CBC, for example, competes with other media and entertainment platforms for Canadians' leisure time. Indeed, like other traditional media, the $\mathrm{CBC}$ has

19 Canadian newspapers have lost 96 percent of their advertising revenues since 2008 (Wells 2017).

20 The panel has proposed a mechanism administered by the Canada Revenue Agency that relies on objective criteria as far as possible for the receipt of these funds. 
responded to recent trends by trying to leverage its brand on platforms other than traditional $\mathrm{TV}$ or radio. One challenge the $\mathrm{CBC}$ has had in this respect is the revealed need to shore up its viewership by offering more popular content arguably, more "fun" or sensational content (Doyle 2019). This content, however, could be provided just as well by private broadcasters and other content providers that compete with the $\mathrm{CBC}$ for viewers and advertising dollars.

Insofar as the CBC fulfils its raison d'être to offer content that private broadcasters typically do not, the fact that it incidentally offers some content that competes with private sector offerings is legitimate, and likely inevitable anyway. However, the idea that its existence is necessary to provide Canadians with Canadian content they would not otherwise engage with should be subject to some test of its actual success in doing so, as is the case with the British Broadcasting Corporation, for example, whose performance is regularly assessed against its stated public purposes by the British regulator Ofcom. In this respect, the CBC could, like other providers and distributors of content, tap into new inducements specifically aimed at connecting Canadians with original Canadian content, as I propose below.

\section{Restrictions on Foreign Ownership}

Must a Canadian-owned business also produce or distribute the content for it to count as Canadian? In many cases, the production and distribution of Canadian cultural content seems to rely on Canadian-owned businesses that engage in these activities. But since there are barriers to foreign direct investment (FDI) in key cultural businesses, it is not clear whether that reliance is an artifact of policy or a sign of a particular advantage Canadians have at promoting and distributing Canadian cultural content.

If this reliance on Canadian businesses in newspapers, film distribution, book retailing and others is an artifact of policy, rather than a sign of the comparative advantage Canadian businesses actually have, then barriers to FDI in these sectors risk restricting both the diversity of the ownership pool and the capital investments available to produce and distribute Canadian content. This, in turn, risks exacerbating the already slumping productivity depicted in Figure 3 and in general making the connection between Canadian creators and the public more arduous than it should be.

Canadian policymakers should consider the abundant examples of foreign firms' financing, making and distributing cultural products that are strongly associated with another country's culture. ${ }^{21}$ A current striking example is the success that US producers are making of Margaret Atwood's The Handmaid's Tale - itself a warning of a dystopian future originally crafted with the former East Germany in mind. Many global behemoths no doubt hold scale advantages over the typical Canadian-owned cultural business, but Canadians in these businesses should benefit from economies of scope in finding Canadian offerings that will connect well with the Canadian public or with a global public with which "Canadian-ness" resonates. A foreign owner removed from the Canadian scene, in contrast, might not easily establish that connection, as demonstrated by the fact that distinctly Canadian businesses thrive in Canada in many sectors open to competition, despite the presence of global giants.

Unless we think that non-Canadian owners would not play by the rules we would expect a

21 Thus, as Dachis and Schwanen (2016, 15), note, Il Postino, Like Water for Chocolate, Shakespeare in Love, Priscilla Queen of the Desert and Fargo, which many associate culturally with Italy, Mexico, England, Australia, and the United States, respectively, were released by companies based in another country. 
Canadian owner to abide by ${ }^{22}$ - for example, if we thought they would discriminate against Canadian offerings for the Canadian or international market we should remove barriers to foreign ownership per se. Canadian Heritage would still vet foreign owners carefully for any threat that the investment might lessen the access of Canadian or foreign audiences to Canadian content, in the same way that it now vets new foreign investments in cultural industries below a small monetary threshold ${ }^{23}$ or purchases by a foreign company of an existing foreign-owned cultural business in Canada. In the latter case, acquirers are already required to make commitments compatible with the goals of Canadian cultural policy (Joneja 2013). This practice could be extended to all foreign investments at the same time as Canada becomes more open to them. At a minimum, the federal government should demonstrate how any remaining disallowance of foreign ownership positively contributes to strengthening the domestic (as opposed to just domestically owned) industry in which it is in effect.

That being said, foreign investment policy should be especially calibrated vis-à-vis investments originating in countries that consider it fit, for security, cultural or other reasons, to maintain barriers to Canadian and other foreign investment in activities related to culture. Ideally, opportunities should be reciprocal. But in general, foreign countries have relaxed rules concerning the involvement of foreign players in their cultural and communications marketplace in recent years (Hunter, Iacobucci, and Trebilcock 2010), while Canada's barriers to foreign investment in audio-visual and broadcasting sectors remain well above those of the typical member country of the Organisation for Economic Co-operation and Development (OECD 2018a, 2018b). In the United States, for example, the Federal Communications Commission has begun rolling back some restrictions on foreign ownership of broadcast station licences, although leaving them in place for owners, in a bid to encourage "new sources of investments in the broadband industry."

In short, denial of a proposed acquisition by a foreign owner, in this as in other sectors, should be based on reasoned concerns about would-be foreign investors acting contrary to Canada's interest writ large, including whether their share of the Canadian market or their behaviour might negatively affect, through anti-competitive practices, the ability of Canadian content to reach the public.

\section{WHAT IS TO BE DONE?}

Those in the media sector who rely on Canadian exhibition quotas or on compulsory spending by private broadcasters, but who now see the quotas potentially bypassed, the compulsory spending potentially dry up and advertising revenues swept away by much more effective engines than traditional media, naturally worry. The response of politicians to these worries often focuses, also naturally enough, on what they can do to maintain existing jobs. Often, they assign blame to providers that have disrupted the old ways of doing things by

22 It is certainly possible to screen these investors for their good business experience and good character and integrity, as one would screen applicants for a banking licence, for example.

23 Heritage Canada considers whether the investment will be "promoting the creation, dissemination and preservation of diverse Canadian content; cultural participation and engagement, fostering and strengthening connections among Canadians; and active citizenship and civic participation" (Facey and Krane 2017, 52). Note that, unlike FDI rules applying to other businesses, Heritage Canada requires undertakings by a foreign investor to be made in perpetuity (53). 
introducing or exploiting new technologies. ${ }^{24}$

Neither reflex, however, is helpful in creating the conditions for the future success of cultural policy, which needs to be founded on the ability to connect Canadian content with its potential audiences, on the platforms and through the media these audiences find most convenient. This would include journalistic content generated and curated by traditional media. But since the traditional media can reinforce stereotypes or ignore alternative views (Dobson 2019), the policy picture should be nested in a broader one of access by Canadians to digital platforms that provide a vital and interactive conduit to a diverse Canadian cultural and information landscape. Ultimately, the focus should be on high-quality, engaging or useful content, not quantity of content.

Besides, producers and distributors of Canadian content now seem to have, from a technological standpoint, as many opportunities to connect with their audiences as everyone else through the internet and ubiquitous personal communications devices. What they might not have is the scale that giant platforms and providers of digital services have reached, and that allows them to reach audiences, and even direct audiences toward certain content. This raises the question of the competitive environment within which Canadian content reaches potential audiences. ${ }^{25}$

\section{Competition Copyright and Taxation Issues}

In devising policy, a fundamental question to ask is whether the digital age - which is bringing new means of reaching the public and hence new forms of competition - is also facilitating the emergence of a market in which a few dominant gatekeepers and other players could engage in anti-competitive practices such as predatory pricing, refusal to deal and abuse of dominance. If so, is Canada's competition regime adequate to the task of dealing with such a problem?

The C.D. Howe Institute's Competition Policy Council has concluded that Canada's competition authorities have the tools to address anti-competitive behaviour by digital giants in the Canadian marketplace (Competition Policy Council 2019). Nevertheless, Canadians will follow with interest the slew of official inquiries in the United States into the competitive practices of data-driven internet giants, including inquiries into how search results are produced and into competition for advertising (Sandler 2019).

Other key rules of the market for cultural and information products that must be considered relate to the treatment of intellectual property. As mentioned, the review of the Copyright Act is proceeding on a separate track from the legislative review of the Broadcasting and Telecommunications Acts, and speaks to the fair treatment of Canadian culture and information producers in the marketplace. Canada's cultural sector should not count on likely reforms, however, to tilt much the balance their way between the goal of fairly rewarding creators and others who own the rights to cultural or entertainment content, on the one

24 See, for example, a recent exchange in the House of Commons over the paying off of 68 employees by Quebec broadcaster TVA, which the company blamed on unfair competition from "web giants," in which the Canadian heritage minister said that the loss of even just one job was a tragedy, "particularly when it affects the culture and communications sector." Available online at https://openparliament.ca/debates/2019/6/5/pablo-rodriguez-1/.

25 A useful overview of why cultural products are not like "ordinary commodities," requiring special attention from competition authorities, copyright rules, and the role of the advertising market as discussed below is provided Grant and Wood (2004), Appendix B. 
hand, and that of making cultural and information products available as widely as possible for educational and creative purposes, on the other.

Although a natural tension between these two goals lies at the very heart of the copyright system, a recent House of Commons committee report generally ran counter to recommendations for stronger forms of copyright protection (such as limiting exceptions for fair dealing) made by Heritage Canada (Geist 2019). Instead, the economic argument in favour of more widespread access to content and information prevailed in the committee report. However, the Canada United States Mexico Agreement reached in late 2018 does provide for longer copyright protection and emphasizes enforcement. And, as noted by Boyer (2019), with technologies allowing the reproduction of content at practically zero marginal cost, it is fair to continue to examine novel approaches for compensating creators for the use of their work.

Another question related to fair competition has to do with the taxation of internet-based digital platforms that naturally operate in Canada but are not based here, and that have attracted revenues from Canadian firms advertising for the Canadian marketplace. It is inaccurate to describe this purchase by advertisers as "taking $\$ 7$ billion dollars out of the Canadian economy," as the Journalism and Written Media Independent Media Panel of Experts (2019) did in its report, since Canadian advertisers presumably are getting good value for their money. Nevertheless, it is potentially taking business away from similar entities that are taxed more heavily by virtue of being headquartered in Canada. As discussed above, I propose restoring parity in the marketplace - without taking away the ability of Canadian advertisers to reach their potential customers via the most cost-efficient means available - by allowing Canadian advertisers to deduct only advertising expenses placed with any entity, Canadian or foreign, that remits Canadian sales taxes and pays income taxes commensurate with its business in Canada. In that light, it is passing strange that Canadian governments (except in Quebec and Saskatchewan) have exempted Canadians from paying sales taxes on content subscriptions or other services purchased from companies not located in Canada, such as Netflix. This makes no sense from a fiscal policy perspective (Wyonch 2017) or from a cultural policy perspective. Apple's iTunes service started voluntarily charging Canadian sales taxes on purchases from its Canadian customers in January 2019. Amazon also charge sales tax on certain memberships and subscriptions. What they are doing, others should also be mandated to do.

In general, however, Canadian cultural policy should not be adopted in splendid isolation from other issues confronting Canada's economy and society. It should embrace a "first do no harm" approach toward all sectors, including the cultural and information sectors, as Canadians seek to capture the benefits and grapple with the consequences of new digital technologies. This means not restricting unnecessarily how Canadians use the market to access, upload content and do business via the internet, or imposing a tax on internet connectivity more broadly that would finance only cultural activities.

What policies, then, could encourage Canadians to enjoy, consume or use Canadian cultural content more willingly in the digital era? I propose a strategy with two new strands: 1) enhancing the discoverability and contestability for Canadian content; and 2) redirecting some existing funding toward a more pointed Canadian Connections Program, offered on a more competitive basis.

\section{Discoverability and Contestability for Canadian Cultural Products}

Since 2014, as it prepared for the "Let's Talk TV" consultations, the CRTC has pushed the industry and government policymakers to examine ways to promote the "discoverability" of Canadian content. The concept of discoverability as it applies to this discussion is not about the ability of consumers, who know what they are looking for, to find the 
Canadian content they seek. Rather, it is about increasing the chances, as audiences look for sources of education, entertainment or information amid the cornucopia of offerings available on various platforms, that the content they find is Canadian.

Making Canadian content more "discoverable," in the sense of more likely to be found by consumers who are not necessarily looking for it, can be a challenge given the availability of a seemingly infinite array of content from any source. Yet there are now sophisticated ways to exploit users' data collected online and through other interactions - to discover what kind of content, including Canadian content, might interest them.

A serious effort to promote discoverability could include forming a consortium to foster the use of search engine optimization techniques ${ }^{26}$ for sites featuring Canadian cultural or information content, and online advertising to drive potential consumers to Canadian content that potentially accords with their other likely preferences. ${ }^{27}$ The consortium could also offer a new free mobile application for Canadian cultural and information programming, feeds and individual offerings from all sources. The app could direct users to different genres or regional content - offerings that meet a certain Canadiancontent ratio depending on the genre selected, the way the CRTC now allows Canadian content to vary for Indigenous, jazz and ethnic radio licences, for example. The consortium could promote programming available anywhere in that country and entirely devoted to up-and-coming artists from all over the world as exists in Australia. ${ }^{28}$

A discoverability strategy would also support stronger collaboration, along the vertical chain from artists and studios to the public, on marketing plans for Canadian content. This would include encouraging content producers, broadcasters and distributors to collaborate more closely on the development and marketing of content (see Canadian Media Fund 2019, 55-6). Going in this direction might involve broadcasters' taking on a greater role in developing original audiovisual material, as Hunter, Engelhart, and Miller (2017) envisage, with the support of the proposed Canadian Connections Program I describe below.

As Burri $(2019,8)$ notes with respect to online content, "the content that is supported and endorsed, often by public money, is valuable to citizens only if it can be found and accessed online." Pre-competitive collaboration toward enhancing the discoverability of Canadian content as a whole, in the ways described above, would strengthen the willing connection between Canadian content and Canadian audiences, and hence make public support for Canadian cultural endeavors more effective overall. It would also have the virtue, being mostly internet-based, of enabling this content to reach foreign audiences better - boosting the chances of global economic success for cultural products that can be digitized.

From the standpoint of cultural policy, the key policy objective remains for Canadians to enjoy or use Canadian content more - to want to see it or hear or read it. To that effect, I also suggest redirecting subsidies that currently support production toward rewarding success in making Canadians appreciate and willingly engage with Canadian content, especially new content that might otherwise struggle commercially.

26 Webopedia defines search engine optimization as "a methodology of strategies, techniques and tactics used to increase the amount of visitors to a website by obtaining a high-ranking placement in the search results page of a search engine"; see https://www.webopedia.com/TERM/S/SEO.html.

27 As with current support programs such as tax credits, certain genres such as pornography would be made ineligible.

28 Triple j brands itself "the place for the best new music from around Australia \& the world"; see https://www.abc.net.au/ triplej/. 


\section{Supporting the Market for Canadian Cultural Offerings: A Canadian Connections Program}

A Canadian Connections Program, along the lines initially suggested by Dachis and Schwanen (2016, 7), would reward success in demonstrably engaging Canadians with Canadian cultural and information products beyond what the marketplace would provide. It would complement the work of agencies such as the NFB and programs delivered through Telefilm Canada that support research, innovation and development or original exhibition in a context of high fixed costs and uncertain demand for original cultural creations. Such existing programs seem well attuned to the rationales for cultural subsidies.

This new program would pay more attention to connecting (and developing) supply with potential demand. It would fund entities - publishers, broadcasters and internet-based distributors of cultural or information products - that successfully connect Canadian offerings, whose commercial viability has not been established, with a Canadian audience. It would replace programs that mainly support production activities - such as the refundable tax credit for Canadian-owned film productions and direct funding by government of the Canadian Media Fund - with support for juried, multiyear marketing plans that show the most promise for connecting such offerings with audiences.

The funding awarded through this program would not be limited to one cultural industry in particular. It could be administered by the Canadian Media Fund, whose ambit for this purpose would expand beyond audio-visual content. The fund would periodically call for proposals meeting minimum criteria with respect to type of content for example drama, amateur sports, documentary, children's, public affairs or minority language programming - and projected audiences. Proposals would be evaluated by a jury of experts according to their originality in relation to commercially available content and the credibility of their plan for connecting Canadians with this content - perhaps with special weight attached to the targeting of identifiable minority audiences or for content available across a number of provinces. Naturally, the jurors could not be political appointees or prospective recipients of subsidies. Successful recipients of subsidies would be bidders that offered to meet the minimum criteria for the least amount of requested subsidy, a format for funds allocation known as a "reverse auction." Bidders for subsidies could be Canadian broadcasters, including the $\mathrm{CBC}$, or other Canadian or foreign services offering cultural or information content to Canadians, likely working in partnership with various producers of Canadian content themselves.

This program would also replace Canadiancontent rules - although not rules that require some Canadian channels being made prominently available throughout the country - and Canadiancontent funding requirements for broadcasters administered by the CRTC. The subsidies it dispensed would be available only to entities with which Canadian advertisers could deduct advertising expenses. Funding for the program would come out of general government revenues. As noted, imposing a special tax on overall internet services that benefit virtually all Canadians - as the CRTC chair, for example, has suggested in order to fund Canadian cultural programs (Menzies 2019) - would contradict the goals of access to and development of the digital economy (see also Dachis and Schwanen 2016, 7).

\section{CONCLUSION}

There is no measure of "sufficient" production or consumption of Canadian content. In the absence of public support, what Canadian cultural output would in fact be produced or consumed is a matter of conjecture. At the same time, the positive externalities generated for Canadians by cultural activities writ large and certain elements of the economics of producing cultural products that can be easily replicated in digital forms suggest that they would be underprovided and underconsumed in the unfettered market. 
Although certain types of cultural activities are similar to research and development and might warrant support on similar grounds, the ultimate test of a successful cultural policy is whether Canadian cultural productions connect with their potential public and other users. This test is fundamentally one that requires paying attention to the potential demand for Canadian offerings, in contrast to measuring success via common metrics of economic activity such as jobs or GDP, which could be invoked as a basis for supporting any economic sector.

Canada's cultural policies need to become better suited to the digital age, while still reflecting the underlying rationales for such support. To that end, a number of policy tools should be replaced or revamped, including content and funding requirements for broadcasters and for broadcast distribution units, certain tax credits and direct funding of audio-visual and journalistic production, and prohibitions on foreign investment. Instead, there should be new investment in tools that enhance the discoverability of Canadian content, and a more rigorous focus - whose success should be periodically evaluated - on subsidizing cultural activities on the basis of their likelihood of connecting non-commercially available Canadian content with Canadian and foreign audiences.

Policy success lies in whether government policy can effectively increase the audience, readership or viewership for Canadian content, including subsidized content that in time becomes a commercial winner. That, ultimately, is how to ensure a successful, and widely supported, cultural policy. 


\section{REFERENCES}

Arrow, Kenneth. 1974. The Limits of Organization. New York: W.W. Norton.

Boyer, Marcel. 2019. "How to Fix Copyright in the Digital Age.” Intelligence Memo. Toronto: C.D. Howe Institute. May 13.

Browne, Dennis. 1998. "Canada's Culture/Trade Quandary and the Magazine Case." Canadian Parliamentary Review. Autumn.

BTLR (Broadcasting and Telecommunications Legislative Review). 2019. What We Heard Report. June.

Burri, Mira. 2019. "Discoverability of Local, National and Regional Content Online: Mapping Access Barriers and Contemplating New Orientation Tools.” Discussion paper. Ottawa: Canadian Heritage. February.

Canada. 2016. Canadian Content in a Digital World - Focusing the Conversation. Consultation Paper. Ottawa.

. 2018. "Broadcasting and Communications Legislative Review - Terms of Reference." Ottawa. Available online at https://www.ic.gc.ca/eic/site/110. nsf/vwapj/terms_of_reference_EN.pdf/\$FILE/ terms_of_reference_EN.pdf.

.2019a. Canadian Heritage. Canadian Heritage 2019-20 Departmental Plan. Ottawa: Her Majesty in Right of Canada.

2019b. Innovation, Science and Economic Development Canada. Broadcasting and Telecommunications Legislative Review. Ottawa. Available online at https://www.ic.gc.ca/eic/site/110. nsf/eng/home, accessed June 29, 2019.

Canada Media Fund. 2019. Discoverability: Toward a Common Frame of Reference - Part 1. Available online at https://trends.cmf-fmc.ca/wp-content/uploads/ CMF_-_Discoverability_Toward_a_Common_ Frame_of_Reference_-_Final.pdf.

Canadian Communications Foundation. 2019. "The History of Canadian Broadcast Regulation.” Available online at https://www.broadcastinghistory.ca/history-canadian-broadcast-regulation, accessed August 10, 2019.
Canadian Press. 2019. "Film and television production studio planned for the City of Hamilton." June 18. Available online at https://toronto.citynews. ca/2019/06/18/film-and-television-productionstudio-planned-for-the-city-of-hamilton/.

CRTC (Canadian Radio-television and

Telecommunications Commission). 2015. "Let's Talk TV: A Conversation with Canadians.” Ottawa. Available online at https://crtc.gc.ca/eng/talktvparlonstele.htm. . 2018. Harnessing Change: The Future of Programming Distribution in Canada. Ottawa. Available online at https://crtc.gc.ca/eng/ publications/s15/.

- 2019. Communications Monitoring Report 2018.

Competition Policy Council. 2019. Canadian

Competition Policy Toolkit in the Digital Age: Is Today's Toolkit up to the Task? Toronto: C.D. Howe Institute. April.

Dachis, Benjamin, and Daniel Schwanen. 2016. Changing the Channel on Canadian Communications Regulation. Commentary 451. Toronto: C.D. Howe Institute. May.

Dobson, Kathy. 2019. "Connecting, Bypassing, and Networking: Analyzing Idle No More's Online Activities." In Second International Handbook of Internet Research, edited by J. Hunsinger, Matthew M. Allen, and Lisbeth Klastrup, 185-200. New York: Springer.

Doyle, John. 2019. "How low will CBC TV bosses go in search of ratings and ad dollars?" Globe and Mail. July 24.

Facey, Brian A., and Joshua A. Krane. 2017. Investment Canada Act: Commentary and Annotation 2018. Toronto: LexisNexis.

Ferencz, J., and F. Gonzales. 2019. "Barriers to Trade in Digitally Enabled Services in the G20." OECD Trade Policy Papers 232. Paris: Organisation for Economic Co-operation and Development. 
Geist, Michael. 2019. “The Authoritative Canadian Copyright Review: Industry Committee Issues Balanced, Forward-Looking report on the Future of Canadian Copyright Law.”June 23. Available online at https://canispreports.com/threads/theauthoritative-canadian-copyright-review-industrycommittee-issues-balanced-forward-looking-reporton-the-future-of-canadian-copyright-law.6326/.

Globerman, Steven. 2016. “Technological Change and Its Implications for Regulating Canada's Television Broadcasting Sector." Vancouver: Fraser Institute. May.

Grant, Peter S. and Chris Wood. 2004. Blockbusters and Trade Wars: Popular Culture in a Globalized World. Vancouver: Douglas \& McIntyre.

Hunter, Lawson, Edward Iacobucci, and Michael Trebilcock. 2010. Scrambled Signals: Canadian Content Policies in a World of Technological Abundance. Commentary 301. Toronto: C.D. Howe Institute. January.

Hunter, Lawson, Kenneth G. Engelhart, and Peter Miller. 2017. Strengthening Canadian Television Content: Creation, Discovery and Export in a Digital World. Commentary 498. Toronto: C.D. Howe Institute. December.

Joly, Mélanie. 2017. "Launch of Creative Canada.” Speech by the Minister of Canadian Heritage, Ottawa, September 28. Available online at https://www.canada.ca/en/canadian-heritage/ news/2017/09/creative_canada_-avisionforcanadascr eativeindustries.html.

Joneja, Navin. 2013. Regulation of Foreign Investment in Canada: The Investment Canada Act - Law, Policy and Practice. Toronto: Thomson Carswell.

Journalism and Written Media Independent Panel of Experts. 2019. Report. [n.p.]. Available online at https:/www.globalphilanthropy.ca/images/uploads/ English-Panel-Report-20190717_journalism.pdf.

Kymlicka, Will. 1991. Liberalism, Community and Culture. New York: Oxford University Press, Clarendon Press pap.

Menzies, Peter. 2019. "Ottawa's conflicting policy directives mean a tough road for CRTC chair Ian Scott." Globe and Mail. July 3.
OECD (Organisation for Economic Co-operation and Development). 2018a. "Services Trade Restrictiveness Indices (STRI) Note: Audio-Visual Services, Sound Recording." Paris: OECD. Available online at https://www.oecd.org/trade/topics/ services-trade/documents/oecd-stri-sector-notemotion-pictures.pdf.

_. 2018b. "Services Trade Restrictiveness Indices Note: Broadcasting." Paris: OECD. Available online at https://www.oecd.org/trade/topics/services-trade/ documents/oecd-stri-sector-note-broadcasting.pdf.

Payne, A. Abigail. 2003. Role of Government Panel: The Culture Industry." Available online at https://www. researchgate.net/publication/254977522_Role_ of_Government_Panel_The_Culture_Industry/ link/54ab4a270cf25c4c472f75da/download.

Putnam, Robert D. 1995. “Bowling Alone: America’s Declining Social Capital.” Journal of Democracy 6 (1): 65-78.

Sandler, Rachel. 2019. "Breaking Up Big Tech: Facebook, Google Now Face 4 Separate Antitrust Investigations." Forbes. September 9.

Schwanen, Daniel. 1997. A Matter of Choice: Toward a More Creative Canadian Policy on Culture. Commentary 91. Toronto: C.D. Howe Institute. April.

. 2001. "A Room of Our Own: Cultural Policies and Trade Agreements." IRPP Choices 7 (4): 1-28.

Statistics Canada. 2017. "Daily average time spent in hours on various activities by age group and sex, 15 years and over, Canada and provinces," Table 45-10-0014-01. Ottawa. Available online at https://www150.statcan.gc.ca/t1/tbl1/en/ tv.action?pid=4510001401, and earlier versions of the General Social Survey: Time Use.

Sweeney, Mark, and Tara Conlan. 2019. "Netflix to spend $\$ 500$ million on British-made TV shows and films.” Guardian. September 20.

Taylor, Kate. 2018. "Taking on the culture file, Rodriguez is left to clean up Joly's mess." Globe and Mail. July 18. 
UNESCO (United Nations Educational, Scientific and Cultural Organization). 2019. The Globalisation of Cultural Trade: A Shift in Consumption, International Flows of Cultural Goods and Services 2004-2013. Montreal: UNESCO Institute for Statistics.

Valpy, Michael. 2013. "What binds us together, what pulls us apart.” Toronto Star. December 5.

Von Finckenstein, Konrad. 2017. "Modernizing Communications Legislation.” Intelligence Memo. Toronto: C.D. Howe Institute. May 5.

Wells, Ira. 2017. "Why Canada's New Cultural Policy Will Be Terrible for the Arts.” Walrus. October 3.

World Trade Organization (WTO). 1997. CanadaCertain Measures Concerning Periodicals. Appellate Body Report AB-1997-2. June 30.

Wyonch, Rosalie. 2017. Bits, Bytes and Taxes: VAT and the Digital Economy in Canada. Commentary 487. Toronto: C.D. Howe Institute. August.

Zimonjic, Peter. 2019. "Federal government names organizations that will help spend $\$ 600 \mathrm{M}$ journalism fund.” CBC Nerws. May 22. 
NOTES: 


\section{ReCEnt C.D. Howe Institute Publications}

November 2019 Bordo, Michael D., and Pierre L. Siklos. The Bank of Canada and Financial Stability: A Nerw Mandate? C.D. Howe Institute Commentary 557.

November 2019 Trossman, Jeffrey, and Jeffrey Shafer. “The Big Shakeup: Making Sense of the OECD Digital Tax Proposals.” C.D. Howe Institute E-Brief.

October 2019 Herman, Lawrence L. "Keeping Score: Investor-State Dispute Awards between the US and Canada.” C.D. Howe Institute E-Brief.

October 2019 De Laurentiis, Joanne. Ripe for Reform: Modernizing the Regulation of Financial Advice. C.D. Howe Institute Commentary 556.

October 2019 Omran, Farah, and Jeremy Kronick. Productivity and the Financial Services Sector - How to Achieve New Heights. C.D. Howe Institute Commentary 555.

October 2019 Bishop, Grant. Decision Time: The Alberta Shadow Budget 2019. C.D. Howe Institute Commentary 554.

October 2019 Bauslaugh, Randy. "A Tale of Two Pension Plans: My Experience with a Contingent Pension Plan and the Lessons Learned." C.D. Howe Institute Verbatim.

September 2019 Gros, Barry, and Barbara Sanders. The Quest for Sustainability in Contingent Pension Plans. C.D. Howe Institute Commentary 553.

September 2019 Usher, Alex. "Funding for Results in Higher Education.” C.D. Howe Institute E-Brief.

September 2019 Mahboubi, Parisa. Bad Fits: The Causes, Extent and Costs of Job Skills Mismatch in Canada. C.D. Howe Institute Commentary 552.

September 2019 Blomqvist, Åke, and Rosalie Wyonch. Health Teams and Primary Care Reform in Ontario: Staying the Course. C.D. Howe Institute Commentary 551.

August 2019 Robson, William B.P. Thin Capitalization: Weak Business Investment Undermines Canadian Workers. C.D. Howe Institute Commentary 550.

August 2019 Laurin, Alexandre. "The Paycheck Blues: Why Extra Work is often Not Worth the Effort for Lower-income Families.” C.D. Howe Institute E-Brief.

\section{SUPPORT THE INSTITUTE}

For more information on supporting the C.D. Howe Institute's vital policy work, through charitable giving or membership, please go to www.cdhowe.org or call 416-865-1904. Learn more about the Institute's activities and how to make a donation at the same time. You will receive a tax receipt for your gift.

\section{A REPUTATION FOR INDEPENDENT, NONPARTISAN RESEARCH}

The C.D. Howe Institute's reputation for independent, reasoned and relevant public policy research of the highest quality is its chief asset, and underpins the credibility and effectiveness of its work. Independence and nonpartisanship are core Institute values that inform its approach to research, guide the actions of its professional staff and limit the types of financial contributions that the Institute will accept.

For our full Independence and Nonpartisanship Policy go to www.cdhowe.org. 

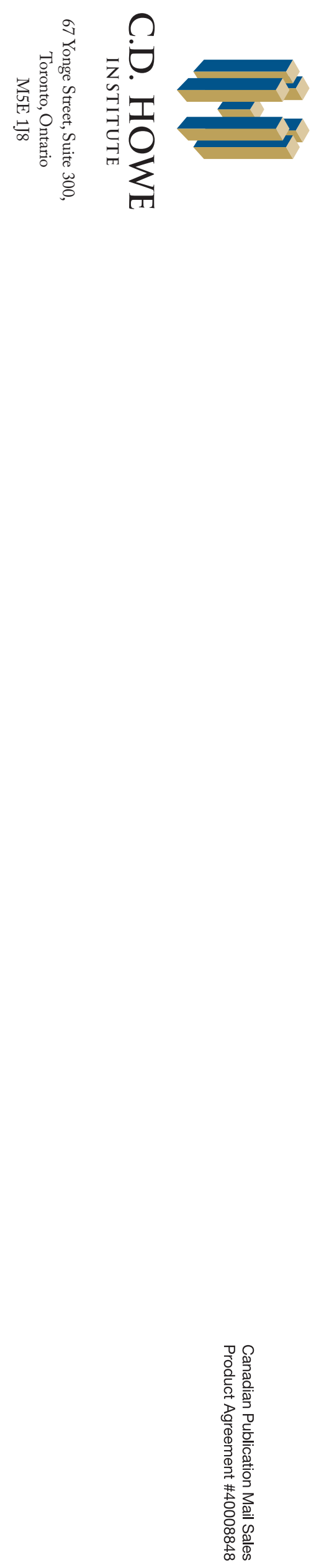